\title{
A brief history of arterial wave mechanics
}

\author{
Kim H. Parker
}

Received: 21 December 2008/ Accepted: 9 January 2009/Published online: 7 February 2009

(C) International Federation for Medical and Biological Engineering 2009

The history of arterial wave mechanics is long and distinguished. The arterial pulse was familiar to Chinese, Indian, Greek and Roman physicians who exploited it regularly in the diagnosis of disease. For more than 3,000 years, palpation of the radial pulse has been a central observation in traditional Chinese medicine. One of the first and best known books devoted to analysis of the arterial pulse is the Mai Jing or Pulse Classic which was written by Wang Shu-he in the late Han dynasty (circa 220 AD) [49]. Pulse diagnosis in India probably has a similar span although it is difficult to know because much of the teaching has been oral, directly from master to student, rather than written. The traditional texts show a detailed knowledge of the arterial pulse, but provide little insight into the mechanics of the pulse, which is hardly surprising since they were developed millennia before the discipline of mechanics was invented.

Galen (129-210 AD) wrote a book On Prognosis from the Pulse [16] in which he describes 27 varieties of pulses and their meaning. He reports experiments from which he concludes correctly that the arteries are filled with blood, not air or spirits as others had asserted. He also carried out experiments that convinced him that the pulsative property of the heart extends from the heart by the walls of the arteries and concluded wrongly that they are filled by 'that pulsific force, because they expand like bellows, and do not dilate because they are filled like skins'. In other words, he felt that the arteries expanded pulling blood into them rather than being expanded by the blood entering from the heart.

K. H. Parker ( $\square)$

Department of Bioengineering, Imperial College London, London, UK

e-mail: k.parker@imperial.ac.uk

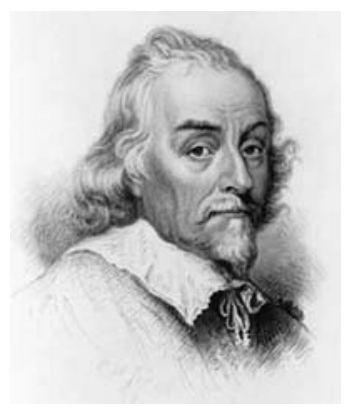

William Harvey

Modern understanding of the cardiovascular system undoubtedly starts with the work of William Harvey (15781657) who published his discovery of the circulation of blood in (Exercitatio Anatomica De Motu Cordis et Sanguinis in Animalibus An Anatomical Disquisition On the Motion of the Heart and Blood in Animals) [21]. Since this work appeared before the invention of the microscope, it is certain that Harvey never saw the capillaries but deduced that there must be small vessels connecting the arteries and the veins. This makes his discovery even more remarkable and a landmark of deductive reasoning, based upon careful observations and a very early application of the conservation of mass, in the face of centuries of teachings to the contrary. Concerning the arterial pulse, Harvey seems to agree with previous workers that the pulse appears in all of the arteries simultaneously supporting his assertion with a quote from Aristotle; 'Aristotle, too, has said, "the blood of all animals palpitates within their veins (meaning the arteries), and by the pulse is sent everywhere simultaneously.",1

\footnotetext{
${ }^{1}$ It is interesting to note that Harvey's second major work, De Generatione (On the Generation of Animals) published in 1651, is much less well known, possibly because one of his conclusions was that copulation was not related to conception in animals.
} 


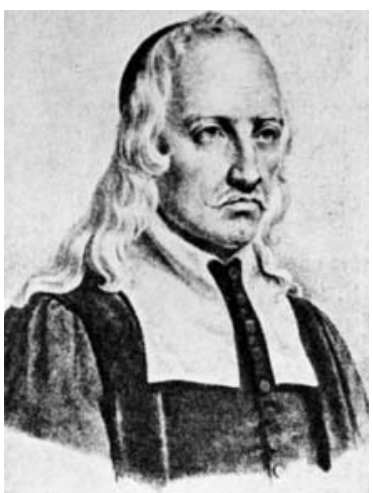

Giovanni Borelli

Giovanni Borelli (1608-1679) is seen by many as the father of bioengineering because of his studies on muscles, joints, the cardiovascular system, respiration, reproduction and many other aspects of the body which were published in De Motu Animalium (On Animal Motion) after his death [4]. He studied the contraction of the heart and its interaction with the arteries. Interestingly, he clearly understood the capacitive effect of the elastic arteries on smoothing the flow of blood (now known as the Windkessel effect).

In Proposition XXXI he states: I do not hesitate to claim that the blood circulates through the body of the animal in a continuous and uninterrupted movement. Although the heart does not pour blood into the arteries during its diastoles, the blood does not stop and remain completely immobile and stagnant in the arteries, viscera, flesh and veins when the heart is at rest. The blood keeps moving but with varying velocity... This results from the fact that the arteries themselves are constricted by contraction of their circular fibres.

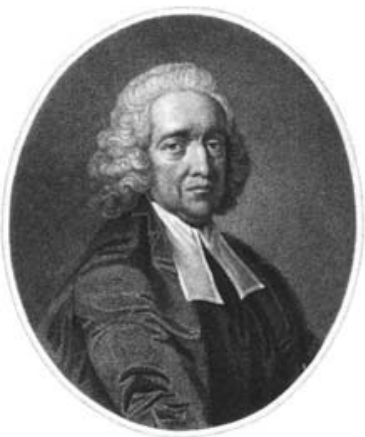

The Reverend Stephan Hales (1677-1746) was a selftaught scientist who successfully combined his scientific explorations with his ecclesiastical duties. In 1733, the Royal Society published a series of papers that he had presented before the society as Statical Essays: containing Haemastaticks [20]. It is full of original observations about the mechanics of the cardiovascular system including the first measurements of in vivo blood pressure. In Experiment 3 , he discusses the velocity at which blood is ejected from the heart of a 10-year-old mare and how it is altered by the elasticity of the arteries:

...the velocity of the blood during each systole will be thrice as much, viz. at the rate of 5204.7 feet, i.e. 0.98 of a mile in an hour or 86.7 feet in a minute $[0.44 \mathrm{~m} /$ s]. Now this velocity is only the velocity of the blood at its first entering into the aorta, in the time of the systole; in consequence of which the blood in the arteries, being forcibly propelled forward, with an accelerated impetus, thereby dilates the canal of the arteries, which begin again to contract at the instant the systole ceases: by which curious artifice of nature, the blood is carried on in the finer capillaries, with an almost even tenor of velocity, in the same manner as the spouting water of some fire-engines, is contrived to flow with a more even velocity, notwithstanding the alternate systoles and diastoles of the rising and falling embolus or force; and this by the means of a large inverted globe, wherein the compressed air alternately dilating or contracting, in conformity to the workings to and fro of the embolus, and thereby impelling the water more equably than the embolus alone would do, pushes it out in a more nearly equal spout.

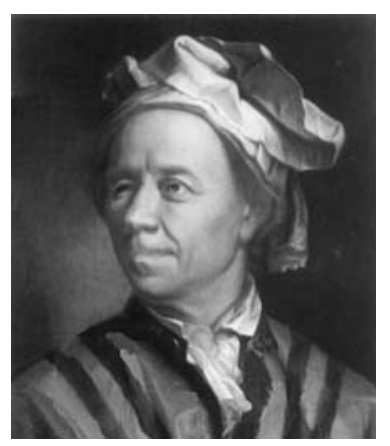

The origin of quantitative mechanics in the cardiovascular system begins, as does so much of quantitative mechanics in general, with Leonhard Euler (1707-1783). In 1755 he submitted an essay Principia pro motu sanguinis per arterias determinando (On the flow of blood in the arteries) as an entry in a prize competition set by the Academy of Sciences in Dijon [8]. In it he set out the one-dimensional equations of conservation of mass and momentum in a distensible tube. In his notation 
I. $\left(\frac{\mathrm{d} s}{\mathrm{~d} t}\right)+\left(\frac{\mathrm{d} \cdot v s}{\mathrm{~d} x}\right)=0$

II. $2 g\left(\frac{\mathrm{d} p}{\mathrm{~d} z}\right)+v\left(\frac{\mathrm{d} v}{\mathrm{~d} z}\right)+\left(\frac{\mathrm{d} v}{\mathrm{~d} t}\right)=0$

where $s$ is the cross-sectional area, $v$ is the average velocity, $p$ is pressure, $g$ is the density of blood, $t$ is time and $z$ is the axial distance.

Euler posited some rather unrealistic constitutive laws (tube laws) for arteries and unsuccessfully tried to solve the equations as he had done for rigid tubes by reducing them to a single equation that could be solved by integration. $\mathrm{He}$ concludes his letter with the plaintive comment; 'In motu igitur sanguinis explicando easdem offendimus insuperabiles difficultates, quae nos impediunt omnia plane opera Creatoris accuratius perscrutari; ubi perpetuo multo magis summam sapientiam cum omnipotentia coniunctam admirari ac venerari debemus, cum ne summum quidem ingenium humanum vel levissimae vibrillae veram structuram percipere atque explicare valeat. ${ }^{2}$ Unfortunately, Euler's letter was lost for nearly a century, the surviving fragments being discovered and published by the Euler Opera postuma project in 1862. The conservation equations set out by Euler were rediscovered, but only in their linearised form, by Wilhelm Weber over a century later (see below).

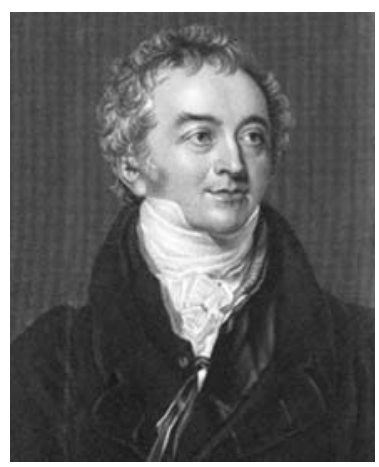

Thomas Young

The next major event in the the history of haemodynamics is the 'Croonian lecture on the functions of the heart and the arteries' delivered to the Royal Society in 1808 by Thomas Young (1773-1829) [60]. In the lecture, he stated the correct formula for the wave speed in an artery but gave no derivation of it. In an associated paper, he does give a derivation which is extremely hard to follow, being based

\footnotetext{
${ }^{2}$ Very loosely translated: If God wanted us to understand flow in the arteries, he would not have made the equations so difficult.
}

on an analogy to Newton's derivation of the speed of sound in a compressible gas, some incomprehensible algebra and numerical guesses [59].

Fourier (1768-1830) did not contribute directly to the mechanics of arteries, his most notable work involving the physics of heat. In his treatise Theorie Analytique de la Chaleur (The Analytical Theory of Heat) in 1822 [10], he asserted that periodic functions can be expressed as the superposition of an infinite series of sinusoidal functions and this observation has had such an impact on arterial haemodynamics that it deserves a mention here. In fact, his assertion is not true for all periodic functions; the first rigorous proof of Fourier's theorem is due to Dirichlet [7] who showed that it is true for piecewise regular functions with a finite number of discontinuities and extrema (conditions that are met by virtually all physiological signals).

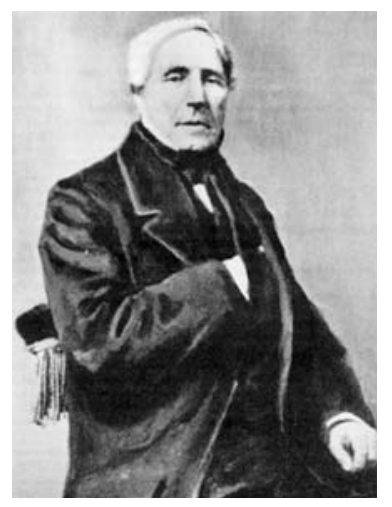

The development by Jean Louis Poiseuille (1799-1869) of his law of flow in tubes is the next landmark in arterial mechanics. Although it is never observed in the arteries because of the pulsatile nature of arterial flow and their complex anatomy of curves and bifurcations, it has become the benchmark against which all other flows in tubes are compared; probably because of its simplicity. Despite its shortcomings, it is cited by many medical and physiological textbooks as the law that governs flow in the whole of vasculature. Poiseuille, who trained as a physician, conducted a very thorough investigation of flow in capillary tubes motivated by his studies of the mesenteric microcirculation of the frog. In 1839, he deposited a sealed copy of his experimental results with the French Academy of Sciences and continued his experiments which were finally approved for publication in 1846 [39]. Poiseuille claimed from his experiments that the volume flow rate $Q$ varied as $Q=\frac{K P D^{4}}{L}$

where $P$ is the pressure drop along the tube, $D$ and $L$ are the diameter and length of the tube and $K$ is a constant that depends on the temperature and the fluid flowing in the 
tube. At nearly the same time Hagen (1797-1884), a German hydraulic engineer, carried out similar experiments on the flow of water in cylindrical tubes with diameters $2.55,4.01$ and $5.91 \mathrm{~mm}$ which he published in 1839 [18]. A least squares fit for the power of the dependency on diameter from his experiments yielded the value -4.12 but he thought that this may have been due to errors in his experiments and suggested the law

$P=\frac{A L Q+B Q^{2}}{D^{4}}$

where $A$ and $B$ are constants depending upon temperature. Hagen appreciated that the $Q^{2}$ term was associated with the generation of kinetic energy in the fluid. At sufficiently low values of $Q$, this relationship reduces to that given by Poiseuille. Although the coefficient of viscosity, introduced by Newton, was used in the study of tube flows by Navier [34] (in which he derived an incorrect version of Poiseuille's law including an inverse dependence on $D^{3}$, the same law cited by Young in his Croonian lecture in 1808), neither Poiseuille nor Hagen incorporated viscosity into their empirical formulae. The first derivation of Poiseuille's law (for horizontal tubes)

$Q=\frac{\pi P D^{4}}{128 \mu L}$

where $\mu$ is the coefficient of viscosity, is usually attributed to Hagenbach [19] who generously suggested that the formula be named after Poiseuille, although there are claims of prior publication on behalf of Jacobson, Neumann, Helmholtz, Stephan and Mathieu [46]. To complicate attribution even further, it seems that Stokes also derived Poiseuille's law from the Navier-Stokes equation as early as 1845 but did not publish the work because he was unsure about the validity of the no-slip condition at the tube walls [45].

The question of the speed of travel of waves in elastic tubes was studied theoretically by Wilhelm Eduard Weber (a noted physicist who is best known for his work on electromagnetism) and experimentally by his brother Ernst-Heinrich Weber (an equally noted physiologist who is considered by many to be the founder of experimental psychophysics) and published in $1866[50,51]$. The theoretical results are based on an independently derivied linearised form of Euler's conservation equations and the assumption of a constant distensibility of the tube $d r=k d p$ where $d r$ is the increase in the radius and $d p$ is the increase in pressure. He derived the equation for the wave speed $c$

$c=\sqrt{\frac{R}{2 k \rho}}$

where $\rho$ is the density of the fluid, $k$ is the radial distensibility defined above and $R$ is the radius of the tube. This is the same relationship as proposed by Young nearly
50 years earlier, but it has the advantage of a rigorous, easy to follow derivation.

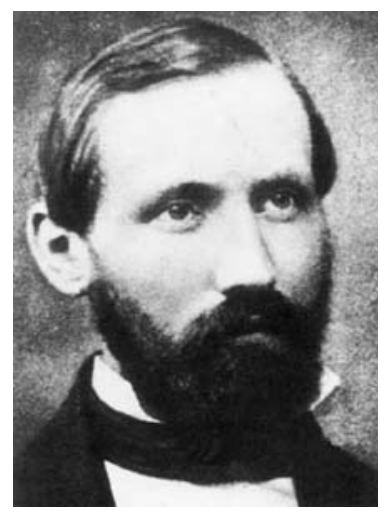

Bernhard Riemann

Georg Friedrich Bernhard Riemann (1826-1866) did not work on arterial mechanics or waves in elastic tubes, but he did make an important contribution to the subject when he published a general solution for hyperbolic systems of partial differential equations in 1860 [41]. His solution was inspired by a problem in gas dynamics but, like Fourier's theorem inspired by heat conduction, it has mathematical implications that transcend its origins. Briefly, his work provides a general solution for a whole class of linear and nonlinear partial differential equations by observing that along directions defined by the eigenvalues of the matrix of coefficients of the differential terms, the partial differential equations reduce to ordinary differential equations. Without knowing, he provided the solution to Euler's equations that Euler had sought in vain.

In 1877-1878, two more important works on the wave speed in elastic tubes were published. Moens (1846-1891) [32] published a very careful experimental paper on wave speed in arteries and Korteweg (1848-1941) [23] published a theoretical study of the wave speed. Korteweg's analysis showed that the wave speed was determined both by the elasticity of the tube wall and the compressibility of the fluid. In the case of blood (which is effectively incompressible) and thin-walled tubes, this reduces to the relationship generally known as the Moens-Korteweg equation for the wave speed $c$

$c=\sqrt{\frac{E h}{2 \rho R}}$

where $E$ is the Young's modulus of the wall whose thickness is $h$.

E.J. Marey (1830-1904) included a chapter on arterial blood flow in his popular textbook of medicine Le circulation du sang ál'état physiologique et dans des maladies (The Circulation of Blood in the Physiological State and in 
Disease) [27]. He cites work by himself and others on the measurement of arterial blood velocity, using Pitot tubes and bristle flow meters. The velocity waveforms he presents look surprisingly similar, given the relative crudity of the methods, to modern waveforms obtained using the latest technology. He shows large reverse flow at the end of systole in more distal arteries such as the femoral artery. For some reason, this work was forgotten and there was heated debate about the nature of flow in the femoral artery in the 1950s.

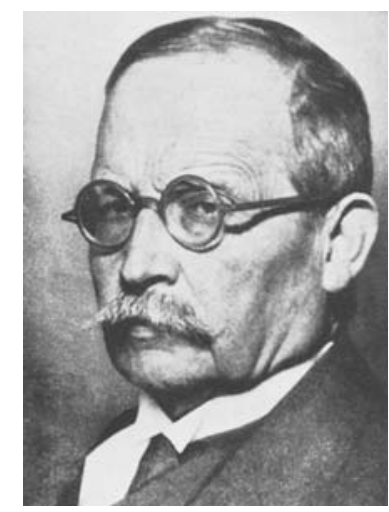

Otto Frank

Otto Frank (1865-1944) was one of the giants of quantitative physiology. He worked primarily on the cardiovascular system and his work has had a lasting effect on the practice of cardiology. His first of many contributions to arterial mechanics was the mathematical formulation of the Windkessel effect in his paper of 1899 Die Grundform des Arteriellen Pulses (The basis of arterial pulses) [11]. He took his inspiration from the work of Stephan Hales, expressing his qualitative arguments in mathematical terms. ${ }^{3}$ He considered the arteries as a single compliant compartment and used the conservation of mass to analyse their change of volume during diastole.

$\frac{\mathrm{d} V}{\mathrm{~d} t}=\frac{P}{w} \quad$ and $\quad \frac{\mathrm{d} P}{\mathrm{~d} V}=c$

where $V$ is the volume of the arterial compartment, $P$ is its pressure, $w$ is the resistance to flow in the microcirculation, and $c$ is a constant (confusingly to modern readers equal to the inverse of the compliance). From these equations, he obtains an exponentially falling pressure

$P=P_{0} \mathrm{e}^{-c t / w}$

where $P_{0}$ is the pressure at the start of diastole. He then considers the systolic part of the cardiac cycle and obtains a

\footnotetext{
3 The term 'Windkessel' is German for 'air chamber', the inverted globe containing air used in early fire-engine pumps, that was used as an analogy of the elastic arteries by Hales. It is a measure of Frank's influence that the English speaking world still uses a German expression for something first described in English.
}

differential equation in terms of the input to the arteries from the heart $i$. Although this equation has a general solution, he seems unaware of it and instead solves it for the special cases $i=$ constant and $i=A \sin B t$.

Frank's next major contribution to arterial mechanics is a series of three papers papers Der Puls in den Arterien (The pulse in the arteries) in 1905 [12], Die Elastizität der Blutgefässe (The elasticity of blood vessels) in 1920 [13] and Die Theorie der Pulswellen (The theory of pulse waves) in 1926 [14]. In the 1905 paper, he introduces the theory of waves in arteries. In the 1920 paper, he correctly derives the wave speed in terms of the elasticity

$c=\sqrt{\frac{\kappa}{\rho}}$

where $\kappa=\frac{\mathrm{d} P}{\mathrm{~d} A} A$ is the inverse of the distensibility of the vessel, $A$ being the cross-sectional area of the vessel. In the 1926 paper, he considers the effect of viscosity, the motion of the wall and the energy of the pulse wave before turning to a number of examples of special cases. These examples include the use of Fourier analysis and probably the first treatment of the reflections of the pulse wave, including the reflection and transmission coefficients due to a bifurcation.

There is a fundamental conflict between the two theories advanced by Frank, the Windkessel and the pulse wave model for arterial mechanics. The Windkessel model assumes that the entire arterial system acts like a single compartment while the wave model predicts that information travels through the arteries in the form of waves. Frank was fully aware of this dichotomy and discussed it, without resolving it, in his 1930 paper Schätzung des Schlagvolumens des menschlichen Herzens auf Frund der Wellen- und Windkesseltheorie (Estimation of the stroke volume of the human heart based upon wave and Windkessel theory) [15]. The failure of the Windkessel theory to describe arterial pressure during systole led to it being abandoned by cardiologists despite its success in describing diastolic behaviour. As Milnor writes: 'The great virtue of the initial Windkessel model was its simplicity, and it still has an explanatory value as a rough approximation that is readily grasped. For almost all research purposes, however, a more detailed and realistic model that conforms to the distribution of properties in the vascular tree is to be preferred.' [30]. The Windkessel-wave dilemma has been revisited recently and is the subject of a paper in this volume [48].

Many clinical cardiologists in the early twentieth century contributed to our understanding of the form and function of the cardiovascular system, but relatively few contributed significantly to our understanding of arterial mechanics. An outstanding exception is Sir James MacKenzie. In medicine, he is best known for his pioneering work on cardiac 
arrhythmias. However, his book The Study of the Pulse, Arterial, Venous, and Hepatic, and of the Movements of the Heart contains many insights into the measurement and the understanding of pressure and flow in blood vessels [26]. Most significantly, he devised the 'polygraph' for the simultaneous measurement of arterial and venous pressure pulses and showed how these waveforms altered in response to various types of cardiac disease.

The analysis of waves in elastic tubes, that is generally associated by modern workers with Womersley (19071958) [56], has a very long history that deserves a chapter on its own. Much of the theory was derived by Gomelka in 1883, including the effects of wall inertia on the wave speed. Unfortunately he published his work in Russian in the Proceedings of the Kazan University which was not widely available to other workers [17]. The problem was further developed by Lamb in his definitive book Hydrodynamics (1879) who formulated the problem in very general terms [45]. His formulation was used by Witzig [55] in a $\mathrm{PhD}$ thesis in the University of Bern where he obtained the general solution for the velocity profiles as a function of vessel radius for rigid tubes. This work was largely unnoticed and his results were rediscovered independently by Morgan and Kiely [33] and Womersley [58]. It was this work that was taken up by McDonald and other researchers for application to arterial mechanics [56-58].

These results rely essentially on the observation that the Navier-Stokes equations are linear for parallel flow, in modern notation $\nabla \mathbf{u}$ is perpendicular to $\mathbf{u}$ for parallel flows and so the nonlinear convective acceleration term in the Navier-Stokes equation is zero because $\mathbf{u} \cdot \nabla \mathbf{u}=0$. The resulting linear equations are then amenable to solution using Fourier methods. In particular, flows with periodic boundary conditions can be solved exactly in terms of the fundamental frequency and all of its harmonics.

A work that deserves wider recognition is the 1940 paper by Apéria [2]. Its undeserved obscurity may be due to its publication in Berlin during the Second World War, which would have limited its dissemination. The paper, entitled Haemodynamical Studies, deals very comprehensively with both the Windkessel model and the 'undulatory' (wave) theory. $\mathrm{He}$ explores the basic assumptions of both theories and their variants and reaches interesting results both theoretically and practically. In one brief passage entitled 'Poiseuille's flow with pressures changing in time' he anticipates the later results of Womersley in a prescient but, given the last sentence, unprophetic way: "The solution for each Fourier term can be got without any special difficulty with power-series with regard to the variable radial distance from the axis $r$, and it leads moreover for every $u(\neq 0)$ to Bessel-functions with complex arguments. Though the complete mathematical treatment is here actually possible, it is of only minor interest to the physiologist."

A very important thread in the tapestry of arterial mechanics has been the application of electrical analogues to the circulation, generally known as impedance methods. This approach to arterial haemodynamics presumes that there is a linear relationship between pressure and flow that is given by an analogue of Ohms law $\tilde{P}=\tilde{Z} \tilde{Q}$, where the pressure $\tilde{P}$ is analogous to the voltage, the flow rate $\tilde{Q}$ is analogous to the current and $\tilde{Z}$ is the impedance. With this analogy, complex RCL electrical networks can be formulated to represent the resistance, capacitance and inertance of the different parts of the vasculature.

According to Milnor [30], "the Fourier analysis of pressure and flow waves ... had been suggested much earlier by Frank (1926) [14], championed by Apéria (1940) [2], and finally introduced into cardiovascular physiology by Porje (1946) [40].' Probably, the first transmission line theory of the arteries was proposed by Landes [25] and developed significantly by Taylor [47].

It is probably not a coincidence that the rapid growth in the application of Fourier analysis to arterial mechanics coincides with the development of the digital computer and the publication of the fast Fourier transform [6] (actually a rediscovery of an algorithm known to Gauss). This meant that Fourier transforms that previously took hours to compute could be calculated in seconds. The success of the impedance method quickly lead to an explosion of work using it: D. A. McDonald and his students (notably W. W. Nichols); M. G. Taylor, who provided much of the theoretical basis, and his students (notably M. F. O'Rourke); Noordergraaf [52] (also see his influential review [36]) and his group (notably N. Westerhof,, who proposed the threeelement Windkessel model [53], and J. K. Li); Milnor [30] and his students. It has been very successful and is now, by far, the most common approach to arterial mechanics [3, 31, 37, 54].

An alternative approach to the problem has been the application of the method of characteristics based upon the work of Riemann [41] to solve the nonlinear form of the conservation equations derived by Euler [8]. The methods were first developed in the field of gas dynamics where there was intense development, both theoretically and experimentally, during and after the Second World War because of the emergence of high-speed flight. The first application of the theory to arterial flows is probably the work of Lambert who applied the theory to arteries using experimental measurements of the radius of the artery as a function of pressure [24]. The approach was developed by Skalak [42] and most completely by Anliker and his colleagues who mounted a systematic study of the different elements of the vascular system with the goal of synthesising a complete description of the arterial system using the method of 
characteristics $[1,22,43,44]$. It is these works that inspired the development of wave intensity analysis [38].

Afterword The author has worked for more than 20 years on the application of the method of characteristics to the cardiovascular system. Although every effort has been made to make this brief historical review as unbiased as possible, it is inevitable that some of my prejudices have coloured both the content and the comments contained herein.

This brief sketch of the long and varied history of the subject has been compiled mainly from secondary sources. Wherever possible, I have consulted the original works but my knowledge of Latin, French, German and Russian is rudimentary at best and I have had to rely upon the comments of others about the original sources for much of the work. I have relied heavily upon Boulanger's detailed and deep study of the history of elastic tube waves for work prior to 1900 [5]. My source for much of the discussion of Poiseuille's law comes from Sutera and Skalak's excellent essay [46]. Truesdell provides his usual sharp and learned commentary about the work of Euler and his antecedents in the introduction to the volume of the Leonhardi Euleri Opera Omnia [9]. Frank's earliest work on the mechanics of the cardiovascular system has been translated and the authors' introduction provides several insights into his extensive body of work on arterial mechanics. [11].

I have chosen to conclude this historical essay in 1960 as that was the date of publication of the first edition of Blood Flow in Arteries by McDonald (1917-1973) [28]. The first edition of this book had limited circulation but a very large influence. A greatly expanded second edition was published after McDonald's death, edited by his daughter, his colleague W. R. Milnor and former student W. W. Nichols [29]. In my opinion, this book marks the beginning of the modern era of arterial mechanics and, incidentally, it contains an excellent historical review that has been most helpful in compiling this short history. Subsequently this book has been revised and expanded as McDonald's Blood Flow in Arteries, currently in its 5th edition [35]. As would be expected from one of the fathers of the impedance method and his students, this book uses the Fourier approach to cardiovascular mechanics almost exclusively and its influence on the subject has been profound. In the context of this special issue, however, it is relevant to quote from McDonald's introduction to the 2nd edition of his book:

The main developments since 1950 have been in terms of treating the whole arterial system as being in a steady-state oscillation produced by the regularly repeated beat of the heart. This describes the pressure pulse as a collection of sinusoidal waves of frequencies determined by the harmonic, or Fourier, series ...
The method of characteristics is also being introduced as a method of improving our analysis of our non-linear system but has not yet undergone any severe experimental testing. Intellectually, these investigations into non-linearity are greatly to be commended. That they receive very little consideration in this book is not because I regard them as negligible but, quite apart from considerations of space, because my emphasis throughout has been on experimental findings. [29] p.12.

Note added in proof See [A] for a discussion of the contributions of Johannes von Kries, a serious omission from this article. [A] Tijsseling AS, Anderson A (2007) Johannes von Kries and the history of water hammer. J Hydr Eng 133:1-8.

\section{References}

1. Anliker M, Rockwell RL, Ogden E (1971) Nonlinear analysis of flow pulses and shock waves in arteries, Part I: Derivation and properties of mathematical model. Z ang Math Phys 22:217-246

2. Apéria A (1940) Haemodynamical Studies. Skand Arch Physiol 83(suppl):1-230

3. Alvolio A (2009) Input impedance of distributed arterial structures as used in investigation of underlying concepts in arterial haemodynamics. Med Biol Eng Comput (this issue)

4. Borelli GA (1680) De Motu Animalium (translated as On the Movement of Animals, translated by Paul Maquet. Springer, Berlin, 1989)

5. Boulanger A (1915) Étude sur la propagation des ondes liquides dans les tayaux élastiques. Travaux et Mémoires de l'Université de Lille, Nouvelle Serie II. Médecine-Sciences, vol 2

6. Cooley JW, Tukey JW (1965) An algorithm for the machine calculation of complex Fourier series. Math Comput 19:297-301

7. Dirichlet JPGL (1829) Sur la convegence des séries trigonométriques qui servent a représenter une function rbitraire entre ces limites données. Mathematik 4:157-169

8. Euler L (1775) Principia pro motu sanguinis per arterias determinando. Opera posthuma mathematica et physica anno 1844 detecta 2:814-823. Ediderunt P.H. Fuss et N. Fuss Petropoli; Apund Eggers et Socios

9. Euler L (1955) Commentationes Mechanicae, Ad Theoriam Corporum Fluidorum Pertinentes. Volumen Posterius. Edidit C.A. Truesdell III; Auctoritate et Impensis Societatis Csientiarum Naturalium Helveticae, Lausannae, pp LXXVI-LXXIX

10. Fourier JBJ (1822) Theorie Analytique de la Chaleur (translated by A. Freeman as The Analytical Theory of Heat. Cambridge University Press, Cambridge, 1878)

11. Frank O (1899) Die Grundform des Arteriellen Pulses. Z Biol 37:483-526 (translated by Sagawa K, Lie RK, Schaefer J, 1990, J Mol Cell Cardiol 22:253-277)

12. Frank O (1905) Der Puls in den Arterien. Z Biol 46:441-553

13. Frank O (1920) Die Elastizität der Blutegefässe. Z Biol 71:255272

14. Frank O (1926) Die Theorie der Pulswellen. Z Biol 85:91-130

15. Frank O (1930) Schätzung des Schlagvolumens des menschlichen Herzens auf Grund der Wellen und windkesseltheorie. Z Biol 90:405-409

16. Galen (2008) The Cambridge companion to Galen. In: Hankinson RJ (ed). Cambridge University Press, Cambridge 
17. Gromeka I (1883) Über die Geschwindigkeit der Fortplanzung der Wellenbewegung der Flüssigkeit in elastischen Rohren. Sammlung der Mitteilungen der physikalisch mathematischen Gesellschaft zu Kazan

18. Hagen GHL (1839) Uber die Bewegung des Wassers in engen cylindrischen Röhren. Poggendorf's Annalen der Physik und Chemie 46:423-442

19. Hagenbach E (1860) Uber die Bestimmung der Zähigkeit einer Flüssigkeit durch den Ausfluss aus Röhren. Poggendorf's Annelen der Physik und Chemie 108:385-426

20. Hales S (1733) Statical Essays: contining Haemastaticks (reprinted No. 22, History of Medicine Series, Library of New York Academy of Medicine Hafner Publishing, New York, 1964)

21. Harvey W (1628) Exercitatio Anatomica De Motu Cordis et Sanguinis in Animalibus (translated as movement of the heart and blood in animals by K.J. Franklin, Blackwell, Oxford, 1957)

22. Histand MB, Anliker M (1973) Influence of flow and pressure on wave propagation in the canine aorta. Circ Res 32:524-529

23. Korteweg DJ. Over voortplantings-Snetheid van Golven in elastische Ruizen. Aca. Proefschrift, Leiden, Bd. V. 525-542

24. Lambert JW (1958) On the nonlinearities of fluid flow in nonrigid tubes. J Franklin Inst 266:83-102

25. Landes G (1946) Die Berechnung des Schlagvolumens mit Berücksichtigung der Reflexionen, verteilter Elastizität, Masse and Reibung. Arch Kreisl.-Forsch 15:1

26. Mackenzie J (1902) The study of the pulse, arterial, venous, and hepatic, and of the movements of the heart. Y.J. Pentland, Edinburgh

27. Marey EJ (1881) Le circulation du sang á l'état physiologique et dans des maladies. Masson, Paris

28. McDonald DA (1960) Blood flow in arteries, 1st edn. Edward Arnold, London

29. McDonald DA (1974) Blood flow in arteries, 2nd edn. Edward Arnold, London

30. Milnor WR (1989) Hemodynamics, 2nd edn. Williams \& Wilkins, Baltimore

31. Mitchell GF (2009) Clinical achievements of impedance analysis. Med Biol Eng Comput (this issue)

32. Moens AI (1877) Over de voortplantingssnelheid van den Pols. Academisch Profschrift, Leiden. B1, pp 1-72

33. Morgan GW, Kiely JP (1954) Wave propagation in a viscous liquid contained in a flexible tube. J Acoust Soc Am 26:323-328

34. Navier CLMH (1823) Mémoire sur les lois du mouvement des fluides. Mém Acad R Sci 6:389-441

35. Nichols WW, O'Rourke MF (2005) McDonald's blood flow in arteries: theoretical, experimental and clinical principles, 5 th edn. Hodder Arnold, London

36. Noordergraaf A (1969) Hemodynamics. In: Schwan HP (ed) Biological engineering. McGraw-Hill, New York

37. O'Rourke MF (2009) Time domain analysis of the arterial pulse in clinical medicine. Med Biol Eng Comput (this issue)

38. Parker KH (2009) An introduction to wave intensity analysis. Med Biol Eng Comput (this issue)

39. Poiseuille JLM (1846) Recherches expérimentales sur le mouvement des liquides dans les tubes de très-petits diamètres. Mèmoires présentes par divers savanta à l'Acad Sci de l'Institut de France 9:433-544

40. Porjé IG (1946) Studies of the arterial pulse wave, particularly in the aorta. Acta physiol scand 13(suppl 42):1-68

41. Riemann GFB (1860) Gesammelte mathematische Werke und wissenschaftlicher Nachlass. Liepzig BG Teubner (ed) 1876, pp 145-164. (originally published as Über die Fortpflanzung ebener Luftwellen von endlicher Schwingungsweite. Technical report, Göttingen 8, 1860, 43)

42. Skalak R (1972) The synthesis of a complete circulation. Chap. 19. In: Bergel D (ed) Cardiovascular fluid dynamics, vol 2. Academic Press, London, pp 341-376

43. Stettler JC, Niederer P, Anliker M (1981) Theoretical analysis of arterial hemodynamics including the influence of bifurcations. Part I: mathematical model and prediction of normal pulse patterns. Ann Biomed Eng 9:145-164

44. Stettler JC, Niederer P, Anliker M, Casty M (1981) Theoretical analysis of arterial hemodynamics including the influence of bifurcations. Part II: critical evaluation of theoretical model and comparison with noninvasive measurements of flow patterns in normal and pathological cases. Ann Biomed Eng 9:165-175

45. Stokes GG (1845) On the theories of the internal friction of fluids in motion, and of the equilibrium and motions of elastic solids. Trans Cambridge Phil Soc 8:287-341

46. Sutera SP, Skalak R (1993) The history of Poiseuille's law. Annu Rev Fluid Mech 25:1-19

47. Taylor MG (1959) An experimental determination of the propagation of fluid oscillations in a tube with a visco-elastic wall; together with an analysis of the characteristics required in an electrical analogue. Phys Med Biol 4:63-82

48. Tyberg JV, Davies JE, Wang Z, Whitelaw WA, Flewitt JA, Shrive NG, Francis DP, Hughes AD, Parker KH, Wang J-J (2009) Wave intensity analysis and the development of the reservoirwave approach. Med Biol Eng Comput (this issue)

49. Wang Shu-He (circa $220 \mathrm{AD}$ ) he Pulse Classic: a translation of the Mai Jing. Yang shou-Zhong (transl.) Blue Poppy Press, Boulder CO, 1997

50. Weber EH, Weber WE (1825) Wellenlehre auf Experimente gegründet, oder über die Wellen tropbarer Flüssigkeiten mit Andwendung auf die Schall- und Lichtwellen. Fleischer, Leipzig

51. Weber WE (1866) Theorie der durch Wasser oder andere incompressibele Flüssigkeiten in elastischen Röhren fortgeplanzten Wellen. Berichte der Gesellschaft der Wissenschaften zu Leipzig: Math phys Kl 18:353-357

52. Westerhof N, Bosman F, De Vries CJ, Noordergraaf A (1969) Analog studies of the human systemic arterial tree. J Biomech 2:121-134

53. Westerhof N, Noordergraaf A (1970) Arterial viscoelasticity: a generalized model. Effect on input impedance and wave travel in the systemic tree. J Biomech 3:357-379

54. Westerhof N, Lankhaar J-W, Westerhof BE (2009) The arterial Windkessel. Med Biol Eng Comput (this issue)

55. Witzig K (1914) Uber erzwungene Wellenbewegungen zaher, inkompressibler Flussigkeiten in elastischen Rohren. Inaugural Dissertation. University of Bern, Bern, Switzerland

56. Womersley JR (1955) Method for the calculation of velocity, rate of flow and viscous drag in arteries when the pressure gradient is known. J Physiol 127:553-563

57. Womersley JR (1955) Oscillatory motion of a viscous liquid in a thin-walled elastic tube. I. The linear approximation for long waves. Phil Mag 46:199-221

58. Womersley JR (1957) An elastic tube theory of pulse transmission and oscillatory flow in mammalian arteries. Wright Air Development Centre, Technical Report WADC-TR

59. Young $\mathrm{T}$ (1808) Hydraulic investigations, subservient to an intended Croonian lecture on the motion of the blood. Phis Trans Roy Soc 98:164-186

60. Young $\mathrm{T}$ (1809) On the functions of the heart and arteries. The Croonian lecture. Philos Trans Roy Soc 99:1-31 